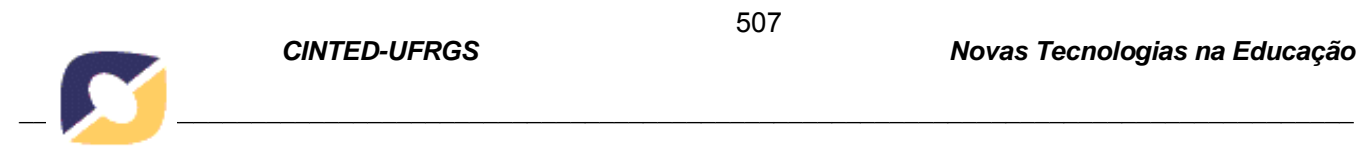

\title{
Mapeamento de Competências Digitais para o aluno dos Anos Iniciais - COMPDig_AI
}

\author{
Patricia Alejandra Behar - UFRGS - patricia.behar@ufrgs.br \\ Gabriella Thais Schorn - UFRGS - schorngabriella@ gmail.com \\ Ketia Kellen Araújo da Silva - UFRGS - ketiakellen@gmail.com
}

\begin{abstract}
Resumo. Este artigo tem como objetivo apresentar o quadro referencial COMPDig_AI, resultado de um mapeamento de competências digitais para o aluno dos Anos Iniciais. Trata-se de uma pesquisa do tipo qualitativa, de procedimento bibliográfico e com finalidade exploratória. O mapeamento foi desenvolvido a partir de três etapas: 1) Levantamento baseado em referencial teórico; 2) Levantamento documental em nível nacional e internacional e 3) Organização do mapeamento das Competências Digitais para o aluno dos Anos Iniciais em um quadro referencial. Os resultados obtidos representam avanço nas pesquisas acerca da temática, contribuindo para que professores possam garantir aos alunos, através do desenvolvimento das $\mathrm{CD}$, as aprendizagens necessárias para a Era Digital. $\mathrm{O}$ próximo passo é implementar o COMPDig_AI através de estratégias pedagógicas em uma turma de alunos dos Anos Iniciais.
\end{abstract}

Palavras-chave: Competências Digitais. Anos Iniciais. Tecnologias Digitais.

\section{Digital Competences Mapping for Elementary School Students - COMPDig_AI}

Abstract. This article aims to present the frame COMPDig_AI, the result of a digital competences (DC) mapping for the students of the Elementary School (ES). This is a research of the qualitative type, of a bibliographic procedure and with an exploratory purpose. The mapping was developed from three stages: 1) Survey based on theoretical reference; 2) Documentation survey at national and international level and 3) Organization of the mapping of Digital Competencies for the student of the Initial Years in a frame of reference. The results obtained represent advances in research on the subject, helping teachers to guarantee the students, through the development of the CD, the necessary learning for the Digital Era. The next step is to implement COMPDig_AI through pedagogical strategies in a class of Early Years students.

Keywords: Digital Competence. Elementary School. Digital Technologies.

\section{Introdução}

A ubiquidade de informações é realidade no Século XXI. Dessa forma, uma mudança de paradigmas se faz necessária, buscando acompanhar as modificações de uma sociedade em transformação. No âmbito educacional, não é diferente. Para que a educação possa continuar caminhando sincronicamente com essas mudanças, o trabalho voltado ao desenvolvimento de competências apresenta-se como uma alternativa que busca mobilizar conhecimentos, habilidades e atitudes (sintetizados na sigla CHA) necessários à atualidade. De acordo com Behar et al. (2013, p. 20) "o paradigma educacional vigente na maioria das instituições educativas, centrado na transmissão de conteúdos, não é mais suficiente para a formação 
desses cidadãos". Assim, compreender o que são as competências digitais e quais são necessárias ao perfil de aluno, torna-se essencial na sociedade da Era Digital (BATES, 2017).

Atualmente, as tecnologias digitais para entretenimento fazem parte do cotidiano das pessoas (MACHADO et al., 2016). Por isso, entende-se que, no contexto escolar, mais precisamente nos Anos Iniciais, o aluno possui familiaridade com as tecnologias, entretanto, nem sempre sua utilização é voltada à aprendizagem. Dessa forma, o trabalho a partir do desenvolvimento de competências digitais se faz necessário, uma vez que o discente já encontra-se motivado para utilizar as tecnologias. De acordo com Piaget $(2014$, p. 43) "nunca se encontra estado afetivo sem elementos cognitivos, nem o contrário". Assim, ampliar a aprendizagem combinando metodologias ativas em contextos híbridos possibilita uma compreensão mais ampla e profunda dos conceitos através de questionamentos e experimentação (BACICH; MORAN, 2018).

Com base nestas questões, o artigo apresenta o COMDig_ AI, um mapeamento de competências digitais para o aluno dos Anos Iniciais com base em literatura nacional e internacional. Organiza-se nas seguintes seções: introdução; em seguida, o referencial teórico relacionando os conceitos de competências digitais, o perfil do aluno dos Anos Iniciais da atualidade e sua relação com as Tecnologias Digitais. Na seção três, é apresentada a metodologia, na seção quatro a análise dos dados obtidos e, por fim, as considerações finais.

\section{O aluno dos Anos Iniciais e as Competências Digitais}

O aluno da atualidade relaciona-se com as Tecnologias Digitais (TD) de maneira diferenciada. Diante desse fato, observa-se que este está em constante interação com as TD desde o seu nascimento. Para Silva (2018, p.75), "as gerações que nasceram após a disseminação das TD têm recebido diferentes nomenclaturas, com o propósito de caracterizar este sujeito e sua relação com a tecnologia". Geração Y, Geração Touchscreen, Nativos Digitais, Screen Generation, Google Generation e iGen são algumas das terminologias utilizadas por estudiosos (FANTIN, 2016; SILVA, 2018).

Para Gabriel (2013), o ritmo de inovação desta geração apresenta diferenças significativas. A coexistência de distintas gerações no ambiente de trabalho, por exemplo, potencializa tensões e conflitos, mas também troca e aprendizado mútuos. Na educação, a revolução tecnológica proporciona ao professor o papel de mediador ao ressignificar o uso das TD para enriquecer o processo de ensino e aprendizagem, criando condições para a construção de conhecimentos, habilidades e atitudes (SCHUHMACHER, 2016).

Para definir o perfil do aluno dos Anos Iniciais, considera-se importante analisar a Base Nacional Comum Curricular (BNCC), visando compreender o que se espera desse sujeito. Segundo a BNCC (2018), a ação pedagógica do primeiro e segundo ano do Ensino Fundamental (EF) tem como foco a alfabetização, garantindo a apropriação do sistema alfabético, através da compreensão escrita e leitura de textos, além do desenvolvimento da capacidade de significação e uso das quatro operações matemáticas (BNCC, 2018). Os cinco anos que compõe os anos iniciais são onde a criança desenvolve a linguagem e a capacidade de representação, bem como planeja, organiza e descreve suas ações, além de desenvolver habilidades necessárias à aquisição da escrita e da leitura fluente. Juntamente com esses processos que ocorrem nos Anos Iniciais do EF, o desenvolvimento de competências digitais se faz necessário, iniciando pela alfabetização digital. Por esse motivo, é possível observar a mudança curricular implementada a partir de 2018, onde a BNCC (2018) apresenta as 10 competências gerais, definidas como aprendizagens essenciais, que se desdobram e se inter-relacionam, sendo a quinta delas voltada para a cultura digital. 
Segundo Sancho et al. (2016), os professores devem rever suas antigas práticas, buscando construir conhecimentos e habilidades não descartáveis, encontrando as melhores experiências para o desenvolvimento de competências-chave, em especial, de competência digital. Dessa forma, ao garantir que o/a cidadão/ã domine conhecimentos, habilidades e atitudes necessários para a vida, ou seja, que não são descartáveis, reafirma-se a visão piagetiana de que "o aluno motivado em aula terá mais entusiasmo para estudar e aprenderá mais facilmente" (PIAGET, 2014, p.37), pois irá além de suas necessidades, conhecendo também seus interesses.

De acordo com Behar et al. (2013) e Silva (2018), existem três termos indispensáveis quando se fala em competência digital: alfabetização digital, letramento digital e fluência digital. Referem-se a prática e a experiência do sujeito em relação à utilização das TD. Entende-se que a alfabetização digital configura-se para além do processo de alfabetização tradicional (aprendizagem da leitura e da escrita) e que não pode ser tratada apenas como a compreensão da língua com o digital, pois estes dois conceitos encontram-se imbricados (SILVA, 2018). Para Gómez (2015), se faz necessário preparar o aluno não só para ler e escrever em plataformas digitais, "mas para que se envolvam com esse mundo compreendendo a natureza intrincada, conectada, da vida contemporânea, tornando-se um imperativo épico e também uma necessidade técnica" (GÓMEZ, 2015, p. 21). Já o letramento digital, é a condição de apropriar-se das TD e exercer práticas de leitura e escrita com este novo suporte que é o digital (SILVA, 2018). Por fim, a fluência digital, perpassa a capacidade pessoal, onde ser fluente no uso das TD significa ir além de somente utilizar, mas também selecionar, aprender, avaliar e criar a informação, de acordo com sua necessidade (BEHAR et al., 2013). Verifica-se que são processos distintos, mas de certa forma interligados, pois refletem a prática crescente do sujeito em relação ao uso das TD, adquirindo o nível de fluência ao final de sua experiência (SILVA, 2018).

\section{Metodologia}

Trata-se de uma pesquisa do tipo qualitativa de procedimento bibliográfico com a finalidade exploratória. Portanto, o COMPDig_AI, foi desenvolvido a partir de três etapas:

1) Levantamento bibliográfico de referencial teórico: nesta primeira etapa foi realizado o levantamento bibliográfico acerca das temáticas: competências digitais; competências digitais para o aluno e competências digitais nos anos iniciais com objetivo de mapear as CD já existentes.

2) Levantamento documental em nível nacional e internacional: a partir dos resultados da primeira etapa, verificou-se a necessidade por documentos nacionais e internacionais, assim, foi realizado um levantamento com base teórica principalmente em nível internacional, tendo como foco documentos que retratem o perfil de alunos dos anos iniciais e as competências digitais necessárias.

3) Organização do mapeamento das CD para o aluno dos Anos Iniciais denominado COMPDig_AI: por fim, foi organizado um quadro referencial a partir do cruzamento entre os dados levantados nas etapas 1 e 2 .

Desta forma a pesquisa teve como foco a compreensão do conceito de CD para o perfil de estudante dos Anos Iniciais, buscando mapear quais competências existem na literatura e que são necessárias a este sujeito. Assim, a seguir, é realizada uma análise e discute-se os dados coletados em cada uma das etapas. 


\section{Análise e discussão dos dados coletados}

Nesta seção são apresentados os resultados referentes às três etapas de pesquisa. Na etapa 1, foi realizado o levantamento bibliográfico acerca das temáticas: competências digitais; competências digitais aluno/estudante e competências digitais anos iniciais com objetivo de mapear as competências digitais já existentes. A partir destes resultados verificou-se a importância em realizar uma busca documental em nível nacional e internacional para complementar o estudo.

No primeiro momento, encontrar CD para o aluno no Brasil mostrou-se dificultoso, tendo em vista que os estudos sobre o tema são relativamente recentes no país. Neste sentido, autores como Silva (2018), Pedro e Chacon (2017) e Machado et al. (2016), contribuem com trabalhos correlatos apresentando publicações acerca de CD para o aluno da EAD; CD para alunos precoces e/ou com comportamento dotado e, CD para a inclusão social de idosos, respectivamente. Porém, não foram encontrados artigos relativos a CD para o aluno dos Anos Iniciais. Dessa forma, reitera-se a importância desta pesquisa, visando avançar nos estudos em relação ao tema.

$\mathrm{Na}$ etapa 2, ocorreu o levantamento documental em nível nacional e internacional. Com relação a pesquisa realizada em base teórica nacional, encontrou-se o documento BNCC (2018). Trata-se de um documento de caráter normativo que define as aprendizagens essenciais a serem desenvolvidas em cada etapa da Educação Básica. Objetiva garantir o desenvolvimento de dez competências gerais que se desdobram e se articulam na construção de conhecimentos, habilidades, atitudes e valores (CHAV). A quinta competência, intitulada "Cultura Digital", visa a compreensão, utilização e criação das TD "de forma crítica, significativa, reflexiva e ética nas diversas práticas sociais (incluindo as escolares) para se comunicar, acessar e disseminar informações, produzir conhecimentos, resolver problemas e exercer protagonismo e autoria na vida pessoal e coletiva" (BNCC, 2018).

Diversas áreas são beneficiadas na Competência Geral sobre Cultura Digital, pois é através do uso das TD, que a aprendizagem e o conteúdo proposto podem ser desenvolvidos. Dessa forma, o sujeito torna-se capaz de utilizar ferramentas multimídia para aprendizagem, produção de conteúdo, resolução de problemas, entre outros.

Para construção do mapeamento de referencial bibliográfico internacional, foi realizado um levantamento específico, visando encontrar documentos que sustentem o quadro preliminar de Competências Digitais deste estudo. Foram selecionados os seis trabalhos listados no Quadro 1 que está dividido em País/Localização, Ano, Autor/es e Competências Digitais Gerais.

Quadro 1 - Resumo das Competências Digitais Gerais encontradas

\begin{tabular}{|c|l|l|l|l|l|}
\hline ID & \multicolumn{1}{|c|}{$\begin{array}{c}\text { País/ } \\
\text { Localização }\end{array}$} & Ano & \multicolumn{1}{|c|}{ Autor/es } & Idioma $^{1}$ & \multicolumn{1}{|c|}{ Competências Digitais Gerais } \\
\hline 1 & Irlanda $^{2}$ & 2015 & $\begin{array}{l}\text { BUTLER, } \\
\text { Deirdre } \text { et } \text { al. }\end{array}$ & Inglês & $\begin{array}{l}\text { - Liderando, Aprendendo e } \\
\text { Ensinando } \\
\text { - Gerenciando a Organização } \\
\text { - Conduzindo o Desenvolvimento }\end{array}$ \\
\hline
\end{tabular}

\footnotetext{
${ }^{1}$ Tradução livre das autoras.

${ }^{2}$ Disponível em

< https://www.pdsttechnologyineducation.ie/en/Planning/Digital-Learning-Framework-and-Planning-ResourcesPrimary/Digital-Learning-Framework-for-Primary-Schools.pdf>. Acesso em 18 abr. 2019.
} 


\begin{tabular}{|c|c|c|c|c|c|}
\hline & \multicolumn{3}{|c|}{ CINTED-UFRGS } & \multicolumn{2}{|r|}{ Novas Tecnologias na Educação } \\
\hline & & & & & $\begin{array}{l}\text { escolar } \\
\text { - Desenvolver a Capacidade de } \\
\text { Liderança }\end{array}$ \\
\hline 2 & Catalunha $^{3}$ & 2016 & $\begin{array}{l}\text { CATALUNY } \\
\text { A, Generalitat } \\
\text { de. }\end{array}$ & Espanhol & $\begin{array}{l}\text { - Cultura, Participação e Civismo } \\
\text { Digital } \\
\text { - Tecnologia Digital, uso do } \\
\text { Computador e do Sistema } \\
\text { Operacional } \\
\text { - Navegação e Comunicação no } \\
\text { Mundo Digital } \\
\text { - Tratamento da Informação } \\
\text { Escrita } \\
\text { - Tratamento da Informação } \\
\text { Gráfica, Sonora e da Imagem em } \\
\text { Movimento } \\
\text { - Tratamento da Informação } \\
\text { Numérica } \\
\text { - Tratamento dos Dados } \\
\text { - Apresentação de Conteúdos }\end{array}$ \\
\hline 3 & $\begin{array}{l}\text { Espanha, } \\
\text { Finlândia e } \\
\text { República } \\
\text { Tcheca }^{4}\end{array}$ & 2016 & $\begin{array}{l}\text { SANCHO, } \\
\text { Juana M. et al. }\end{array}$ & Inglês & $\begin{array}{l}\text { - Aprendizagem da Autonomia e } \\
\text { Auto-regulação } \\
\text { - Ensino e Aprendizagem } \\
\text { baseados em Perguntas } \\
\text { - Conhecimento transdisciplinar } \\
\text { ou interdisciplinar, links e } \\
\text { conexões } \\
\text { - Competência Digital } \\
\text { - Aprendizagem Colaborativa } \\
\text { - Oportunidades e limitações para } \\
\text { ancorar o programa DIYLab para } \\
\text { o currículo }\end{array}$ \\
\hline 4 & $\begin{array}{l}\text { Comissão } \\
\text { Europeia }\end{array}$ & 2017 & $\begin{array}{l}\text { CARRETER } \\
\text { O, Stephanie. } \\
\text { VUORIKARI, } \\
\text { Riina. } \\
\text { PUNIE, Yves. }\end{array}$ & Inglês & $\begin{array}{l}\text { - Informação e Literacia de dados } \\
\text { - Comunicação e Colaboração } \\
\text { - Criação de Conteúdo Digital } \\
\text { - Segurança } \\
\text { - Resolução de Problemas }\end{array}$ \\
\hline 5 & $\begin{array}{l}\text { País de } \\
\text { Gales }\end{array}$ & 2018 & $\begin{array}{l}\text { VUORIKARI, } \\
\text { Riina et al. }\end{array}$ & Inglês & $\begin{array}{l}\text { - Cidadania } \\
\text { - Interagindo e Colaborando } \\
\text { - Produzindo }\end{array}$ \\
\hline
\end{tabular}

\footnotetext{
${ }^{3}$ Disponível em

〈https://actic.gencat.cat/web/.content/01_informacio/documents/arxius/Contenidos-ACTIC-orden-2016.pdf>. Acesso em 20 abr. 2019.

${ }^{4}$ Disponível em 〈http://diylab.eu/docs/D1.6_Report_on_Digital_Competence_in_Schools.pdf $>$. Acesso em 20 abr. 2019.
} 


\begin{tabular}{|l|l|l|l|l|l|}
\multicolumn{2}{c}{ CINTED-UFRGS } & & \multicolumn{2}{l}{ Novas Tecnologias na Educação } \\
\hline 6 & Noruega $^{5}$ & 2018 & $\begin{array}{l}\text { SOBY, } \\
\text { Morten. }\end{array}$ & Inglês & $\begin{array}{l}\text { - Dados e Pensamento } \\
\text { Computacional }\end{array}$ \\
\hline & & & $\begin{array}{l}\text { - Desenvolvimento de } \\
\text { Competências Digitais } \\
\text { - Currículo e Avaliação } \\
\text { - Inovação em todo o Sistema } \\
\text { - Dispositivos Móveis } \\
\text { - Uso de Recursos Digitais de } \\
\text { Aprendizagem } \\
- \text { Ambientes de Aprendizagem }\end{array}$ \\
\hline
\end{tabular}

Fonte: Elaborado pelas autoras (2019).

Para dar seguimento ao estudo, a etapa 3 foi realizada a partir da análise e coleta dos dados com base nas etapas 1 e 2 da metodologia. Dessa forma, foi possível a organização de um quadro referencial de competências digitais para os alunos dos Anos Iniciais. Segue o COMPDig_AI:

Quadro 2 - COMPDig_AI: Quadro Referencial de Competências Digitais para o aluno dos Anos Iniciais

\begin{tabular}{|l|l|l|}
\hline \multicolumn{1}{|c|}{$\begin{array}{c}\text { Competências } \\
\text { Digitais }\end{array}$} & \multicolumn{1}{|c|}{ Áreas } & \multicolumn{1}{c|}{ Competências Digitais Específicas } \\
\hline $\begin{array}{l}\text { 1 Alfabetização } \\
\text { Digital }\end{array}$ & $\begin{array}{l}\text { 1.1 Conhecer os } \\
\text { dispositivos } \\
\text { tecnológicos }\end{array}$ & $\begin{array}{l}\text { 1.1.1 Utilização básica do computador (desktop, } \\
\text { notebook) e de dispositivos móveis (smartphone, } \\
\text { tablet) }\end{array}$ \\
\cline { 2 - 4 } & $\begin{array}{l}\text { 1.2 Interagir e } \\
\text { Colaborar }\end{array}$ & 1.2 .1 Recursos básicos de comunicação \\
\cline { 2 - 4 } & $\begin{array}{l}\text { 1.3 Buscar e } \\
\text { gerenciar } \\
\text { informações }\end{array}$ & $\begin{array}{l}\text { 1.3.1 Acessar e pesquisar informações através dos } \\
\text { diversos motores de busca. }\end{array}$ \\
\cline { 2 - 4 } & $\begin{array}{l}\text { 1.4 Resolução de } \\
\text { problemas }\end{array}$ & $\begin{array}{l}\text { 1.4.1 Identificar um problema, dividi-lo em partes } \\
\text { menores, mais simples e buscar um método de } \\
\text { resolução. }\end{array}$ \\
\cline { 2 - 3 } & $\begin{array}{l}\text { 1.5 Cuidados com a a } \\
\text { Saúde e Segurança } \\
\text { Digital }\end{array}$ & $\begin{array}{l}\text { 1.5.1 Esclarecer as vantagens e desvantagens para } \\
\text { saúde física e mental e cuidados com a } \\
\text { segurança digital. }\end{array}$ \\
\hline 2 Letramento \\
Digital & $\begin{array}{l}\text { 2.1 Explorar os } \\
\text { dispositivos } \\
\text { tecnológicos }\end{array}$ & $\begin{array}{l}\text { 2.1.1 Auxiliar o usuário em conhecimentos } \\
\text { intermediários para o uso do computador (desktop, }\end{array}$ \\
\hline
\end{tabular}

\footnotetext{
${ }^{5}$ Disponível em

$<$ http://www.eun.org/documents/411753/839549/Country+Report+Norway+2018_v2.pdf/e8c32816-d56e-40808154-d2f6ca6f9961> Acesso em 18 abr. 2019.
} 


\begin{tabular}{|c|c|c|}
\hline & & $\begin{array}{l}\text { notebook) e de dispositivos móveis (smartphone, } \\
\text { tablet). }\end{array}$ \\
\hline & $\begin{array}{l}2.2 \text { Interagir e } \\
\text { Colaborar }\end{array}$ & $\begin{array}{l}\text { 2.2.1 Clareza da comunicação e interação com o } \\
\text { computador, dispositivos móveis e demais } \\
\text { usuários. Importância da netiqueta (normas } \\
\text { comportamentais em rede). }\end{array}$ \\
\hline & $\begin{array}{l}2.3 \text { Tratamento de } \\
\text { informações }\end{array}$ & $\begin{array}{l}\text { 2.3.1 Tratamento da informação } \\
\text { recebida/encontrada pelo usuário. }\end{array}$ \\
\hline & $\begin{array}{l}\text { 2.4 Programação } \\
\text { em blocos }\end{array}$ & $\begin{array}{l}\text { 2.4.1 Reconhecer padrões nos problemas, } \\
\text { utilizando a menor quantidade de recursos para } \\
\text { resolução. }\end{array}$ \\
\hline & $\begin{array}{l}2.5 \text { Cuidados com a } \\
\text { Saúde e Segurança } \\
\text { Digital }\end{array}$ & $\begin{array}{l}\text { 2.5.1 Utilização de estratégias que lidem de forma } \\
\text { segura e respeitosa com os dados gerenciados, } \\
\text { publicados e encontrados na internet. }\end{array}$ \\
\hline $\begin{array}{l}3 \text { Fluência } \\
\text { Digital }\end{array}$ & $\begin{array}{l}3.1 \text { Avaliar o } \\
\text { conteúdo digital }\end{array}$ & $\begin{array}{l}\text { 3.1.1 Avaliar conteúdo digital e os recursos } \\
\text { explorados, utilizando-os em favor da } \\
\text { aprendizagem. }\end{array}$ \\
\hline & $\begin{array}{l}3.2 \text { Interagir e } \\
\text { Cooperar }\end{array}$ & $\begin{array}{l}\text { 3.2.1 Interagir, cooperar e compartilhar } \\
\text { adequadamente em rede. }\end{array}$ \\
\hline & $\begin{array}{l}\text { 3.3 Criar conteúdo e } \\
\text { informações }\end{array}$ & $\begin{array}{l}\text { 3.3.1 Auxiliar o usuário na criação de conteúdo e } \\
\text { informação nas diferentes tecnologias digitais. }\end{array}$ \\
\hline & $\begin{array}{l}\text { 3.4 Pensamento } \\
\text { Computacional }\end{array}$ & $\begin{array}{l}\text { 3.4.1 Analisar os elementos relevantes e criar um } \\
\text { conjunto regras para a resolução do problema. }\end{array}$ \\
\hline & $\begin{array}{l}3.5 \text { Cuidados com a } \\
\text { Saúde e Segurança } \\
\text { Digital }\end{array}$ & $\begin{array}{l}\text { 3.5.1 Compreender a importância da utilização de } \\
\text { medidas de segurança na rede. Proteger-se e } \\
\text { auxiliar os demais nesta proteção, visando evitar } \\
\text { fraudes e outros problemas. }\end{array}$ \\
\hline
\end{tabular}

Fonte: Elaborado pelas autoras (2019).

$\mathrm{O}$ quadro referencial de $\mathrm{CD}$ foi organizado e dividido em três $\mathrm{CD}$ gerais, além de desmembrado em cinco grandes áreas com quinze CD específicas. Esta organização se deu com base nos trabalhos correlatos em nível nacional de Silva (2018) e Machado et al. (2016), pois considera-se uma melhor forma de visualização do conteúdo.

A divisão em CD gerais parte dos estudos de BEHAR et al. (2013) e Silva (2018), onde mostram que existem três níveis indispensáveis das $\mathrm{CD}$ : alfabetização digital, letramento digital e fluência digital. São processos distintos, mas interligados, refletindo a prática do sujeito em relação ao uso das TD.

As áreas, assim como as CD específicas, também seguiram a mesma organização de Silva (2018) e Machado et al. (2016). Para a divisão em áreas, seguiu-se a lógica de encontrar qual é o objetivo geral da competência, o que a competência visa desenvolver no sujeito. Áreas como conhecer, explorar e avaliar os dispositivos tecnológicos; interagir, colaborar e 
cooperar; buscar e gerenciar, tratar informações e criar conteúdo; resolver problemas, programar em blocos e entender a lógica do pensamento computacional; além de cuidados com saúde e segurança digital, foram abarcadas, visando contemplar o maior número de CD possíveis, tornando o quadro completo de acordo com as necessidades do aluno dos anos iniciais.

Para as CD específicas, buscou-se fragmentar ainda mais, descrevendo qual é o objetivo específico daquela competência. Dessa forma, fica claro o que se busca desenvolver em cada âmbito do quadro e se torna possível pensar em estratégias pedagógicas para desenvolvê-las. A partir das etapas de divisão do quadro referencial em CD gerais, áreas e CD específicas é possível identificar que, através da alfabetização digital, seguida do letramento digital, aumenta-se o nível de complexidade, cujo propósito é alcançar a fluência digital ao final da experiência.

\section{Considerações Finais}

Este artigo teve como objetivo apresentar o quadro referencial COMPDig_AI, resultado de um mapeamento de competências digitais para o aluno dos Anos Iniciais realizado a partir de levantamento bibliográfico e documental. Para Soares e Coelho (2018), os desafios da Era Digital proporcionam mudanças constantes e significativas no contexto social. Todavia, evidencia-se a necessidade de práticas educativas inovadoras levando em consideração o potencial uso das TD no acesso às informações e na comunicação.

A partir do COMPDig_AI, é possível ao professor criar estratégias pedagógicas para garantir o desenvolvimento das CD propostas neste estudo, através da mobilização de conhecimentos, habilidades e atitudes necessárias ao aluno, ou seja, para que ele se torne competente para as experiências da vida real. Desse modo, entende-se que as CD para o sujeito vão além das práticas tradicionais de ensino de aprendizagem, onde o foco encontra-se em avançar qualitativamente no uso das TD no âmbito educacional.

Percebe-se que no Brasil, este estudo é relativamente novo, tendo a BNCC (2018) como principal fonte de mudanças em relação ao desenvolvimento de competências na base curricular. Entretanto, se faz necessário aprofundamentos em relação ao conceito de competências e suas formas de mapeamento e desenvolvimento. Assim, a partir dos resultados desta investigação, serão realizadas formações com alunos de Anos iniciais, cujo objetivo é validar as competências digitais através de estratégias pedagógicas previamente definidas.

\section{Referências}

BACICH, Lilian; MORAN, José. Metodologias ativas para uma educação inovadora. Porto Alegre: Penso, 2018.

BATES, Tony. Educar na Era Digital - design, ensino e aprendizagem. São Paulo: Artesanato Educacional, 2017.

BEHAR, Patricia A. et al. Competências em Educação a Distância. Porto Alegre: Penso, 2013. 
BNCC. Base Nacional Comum Curricular. Ministério da Educação (MEC). 2018. Disponível em <http://basenacionalcomum.mec.gov.br/> Acesso em 4 de jan. de 2019 às 16h16min.

FANTIN, Monica. "NATIVOS E IMIGRANTES DIGITAIS" EM QUESTÃO: crianças e competências midiáticas na escola. 2016. Disponível em <http://www.periodicos.ufc.br/passagens/article/view/3652/3279> Acesso em 14 de mar. de 2019 às $21 \mathrm{~h} 18 \mathrm{~min}$.

GABRIEL, Martha. Educ@r - a (r)evolução digital na educação. São Paulo: Saraiva, 2013.

GÓMEZ, Angél I. P. Educação na Era Digital - A escola educativa. Porto Alegre: Penso, 2015.

MACHADO, Leticia R. et al. Mapeamento de competências digitais: a inclusão social dos idosos. ETD - Educação Temática Digital, Campinas, SP, v. 18, n. 4, p. 903-921, set. 2016. ISSN 1676-2592. Disponível em: <http://periodicos.sbu.unicamp.br/ojs/index.php/etd/article/view/8644207>. Acesso em 09 de jan. de 2019 às 16 h23min.

PEDRO, Ketilin M. CHACON, Miguel C. M. Pesquisas na internet: uma análise das competências digitais de alunos precoces e/ou com comportamento dotado. Educar em Revista, Curitiba, Brasil, n. 66, p. 227-240, out./dez. 2017. Disponível em <http://www.scielo.br/pdf/er/n66/0104-4060-er-66-227.pdf>. Acesso em 21 abr. 2019 às $15 \mathrm{~h} 53 \mathrm{~min}$.

PIAGET, Jean. Relações entre a afetividade e a inteligência no desenvolvimento mental da criança. Rio de Janeiro: Wak Editora, 2014.

SANCHO, Juana M. et al. Report on Digital Competence in Schools: Spain, Finland and the Czech Republic. 2016. Disponível em <http://diylab.eu/docs/D1.6_Report_on_Digital_Competence_in_Schools.pdf>. Acesso em 20 abr. 2019 às 17h12min.

SCHUHMACHER, Vera R. N. et al. A percepção do professor sobre suas competências em tecnologias da informação e comunicação. RENOTE. V. 14 N $^{\circ}$ 1, julho, 2016. Disponível em <https://www.seer.ufrgs.br/renote/article/view/67370/38462> Acesso em 22 abr. 2019 às $22 \mathrm{~h} 50 \mathrm{~min}$.

SILVA, Ketia K. A. da. Modelo de Competências Digitais em Educação A Distância: MCompDigEAD - um foco no aluno. 2018. Tese (Doutorado em Informática na Educação) Programa de Pós Graduação em Informática na Educação, Universidade Federal do Rio Grande do Sul/ UFRGS. Dísponível em <https://www.lume.ufrgs.br/handle/10183/180549> Acesso em 10 de out. de 2018 às $11 \mathrm{~h} 35 \mathrm{~min}$.

SOARES, Franciane A. COELHO, Iandra M. W. S. Desenvolvimento e validação de um instrumento para mapear e avaliar competências no processo de ensino-aprendizagem de língua espanhola. RENOTE. V. 16 Nº 2, dezembro, 2018. Disponível em 


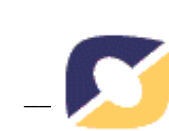

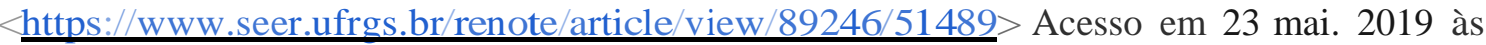
$21 \mathrm{~h} 48 \mathrm{~min}$. 